\title{
Comparison of Internal Forces Redistribution and Displacements Subjected to the Dynamic Wind Gusts depending of Point Fixed Glass Connector Model Shape
}

\author{
Krzysztof Kuliński ${ }^{1 *}$, Przemysław Palacz ${ }^{1}$ \\ ${ }^{1}$ Faculty of Civil Engineering, Czestochowa University of Technology, 42-200 Częstochowa, Akademicka 3 St., Poland \\ * Corresponding author, e-mail: krzysztof.kulinski@pcz.pl
}

Received: 17 April 2021, Accepted: 17 May 2021, Published online: 21 May 2021

\begin{abstract}
This paper presents an analysis of the redistribution of stresses and displacements in numerical models of various shapes of glass connectors. Two states of dynamic wind gusts were analyzed: the maximum value of suction and the maximum value of wind pressure. For the sake of simplicity, wind gusts were assumed periodically as a sinusoidal function. The model adopts a rectangular glass plate that transmits wind pressure and suction through the point fixed glass connectors. Therefore, single-arm cross connectors were not only subjected to bending stress, but also to torsion. Four different shapes of connectors were analyzed. In the first part of the numerical analysis, T-shaped and C-shaped cross-sections were adopted, and in the next part, both connectors were modified by adding fillet welds to the models. The dynamic numerical analysis was performed using the finite element method in the ADINA program.
\end{abstract}

Keywords

spider glass connector, glass fixing, dynamic analysis, ADINA

\section{Introduction}

This nowadays, glass has been used in a variety of ways, especially in civil engineering. Typically, this material is used as part of façades, roofs, stairs, and even as complete floors. Glass is also frequently chosen by architects and engineers to underline the aesthetics of newly designed buildings and to optically extend their interior. It should be noted that in a conventional production process, glass used to be formed as transparent (without any color), whereas modern technology allows designers to obtain glass plates with almost any color and texture. In addition to the aesthetic appeal, sunlight can easily pass through glass, which is desirable from the engineering point of view. Compared to other construction materials where sunlight penetration is strongly limited, glass façades seem to be much more efficient. The other major advantage is the fact that recently designed and built glass façades ensure thermal comfort in the interior for a significantly longer time than the formerly manufactured windows, which is particularly important from the standpoint of sustainable development. Recent studies have focused on smart glass, which is able to adjust its properties to the actual conditions.
For instance, smart glass can change color on sunny days. On the other hand, glass has one substantial disadvantage: it is very brittle and has much smaller compressive and tensile strength compared to popular construction materials such as concrete or steel.

The glass plates used in façades, roofs and other structures have been mostly used as decorative elements. Other essential elements in glass façades and other glass structures include supporting structures and connectors, which transfer the load from glass plates to the structure.

Concerning glass façades, roofs and other structures exposed to external conditions, glass should ensure sufficient strength to resist wind pressure and suction, sufficient strength to bear snow load in the case of horizontal plates, resistance to the temperature fluctuations, resistance to UV radiation etc. Furthermore, windows should also be characterized by adequate thermal insulation. In floors and stairs, glass plates should provide the anti-slippery coating, sufficient resistance to wear, and, importantly, meet specific safety conditions concerning plate cracking. 
Three different types of glass plates have been used in the industry and civil engineering: single-layer standard glass plates, temperature/chemically tempered plates, and laminated plates. Standard singular glass plates used in the past did not meet safety requirements, whereas tempered glass demonstrates higher overall strength. Among other things, tempered glass has been used in the automotive industry as side windows. In case of a car crash, those panes break into very small pieces. The laminated glass plates ensure high safety in case of emergency despite cracking, the plates can be subjected to large deformations. Such laminated plates may withstand a substantial load and offer a relatively higher strength compared to non-cracked plates. Furthermore, the laminated coat usually resists to piercing and glass pieces do not come off from the laminated layer, thus providing extra safety. A study on stress and displacement distribution in laminated glass plates pinned in the corners was published by Sedlacek and Blank [1]. These researchers found that even small values of shear modulus of the foil have an important effect on stress and deformation. Furthermore, the significant effect of temperature on bearing capacity was also observed. Higher temperature values correspond to lower ranges of transferred shear stress. Design details of laminated glass plates have been presented in [2-4].

\section{Glass fixing connectors}

Connectors are a group of components which allow for safe transfer of the load from glass plates to the supporting structure. Based on the scientific description presented in [5], a few different types of connectors can be indicated:

- with respect to the fixing method: joint with ball, joint with ring, rigid,

- with respect of the fixing shape: single, spiders (single to four-arm), two-plane sets (joint, fixed).

The following connectors have been used in glass façades:

- coplanar (one-sided), with the head protruding over the glass surface (two-sided), with the head between the glass plates.

Point connectors may be further subdivided into two groups depending on the type of connection with glass plate. If holes are needed to be drilled in the plate, handle glass fixing is used, whereas in the plates without holes, clamp or glue fixing are usually chosen.

In fact, joint connectors are mainly used for exterior components subjected to the transient loads such as wind. Clamped connectors have been used in places where higher rigidity or higher stability is needed. Spider connectors, depending on the number of arms, are able to support from one to four different glass plates. These connectors are common in glass elevator shafts, as barriers components in stores etc. From the construction point of view, the use of point connectors, which require drilling holes in glass plates, ensures higher safety than the clamped or glued joints. Furthermore, mounting point connectors with the head protruding above the glass plate is faster compared to the glueing method. Design of such connectors is mainly focused on examination of the ultimate limit state. It should be noted that plastic working of the components should be avoided, whereas deformations of the connector should be assumed over a specific range, depending on the glass plate dimensions and load.

\section{Numerical models}

A single-arm spider connecting glass plate with total length of $1.50 \times 1.00 \mathrm{~m}$ to the supporting structure was chosen as a numerical model. Two different shapes of the connector arm cross-sections were analyzed: $\mathrm{T}$ and $\mathrm{C}$-shape. Both connector spider arms were analyzed in two variants: a standard model without visible welds and the welded model, with welds represented as $3 \mathrm{~mm}$ fillets. These connectors were exposed to exterior conditions. Dimensions of the single-arm spiders designed in the study are presented in Fig. 1.

Initially, it was assumed that the spider would be located in the corner of an elevator shaft designed to be built in Gdynia, Poland. The height of the shaft was designed to be equal $25 \mathrm{~m}$. With this assumption and based on [6], the $2^{\text {nd }}$ climatic zone was adopted. Furthermore, it was assumed that the shaft would be located near buildings higher than $15 \mathrm{~m}$, which led to the land development category IV. Since the spider was expected to be located in the corner of the elevator shaft, the highest two wind pressure/ suction coefficients were adopted. Consequently, the loads were $1603 \mathrm{~Pa}$ and $1145 \mathrm{~Pa}$ for suction and pressure, respectively. It should be noted that the pressure/suction load applied to a rectangular plate led to the unsymmetrical load distribution resulting in bending and additional torsion. The dynamic load represented by the sine function was applied to the top surface of the glass plate. Maximum value of suction appeared at $t=1.2 \mathrm{~s}$, whereas maximum value for pressure at $t=3.0 \mathrm{~s}$ of the analysis. Numerical calculations were performed using the ADINA software based on the finite element method. 
(a)

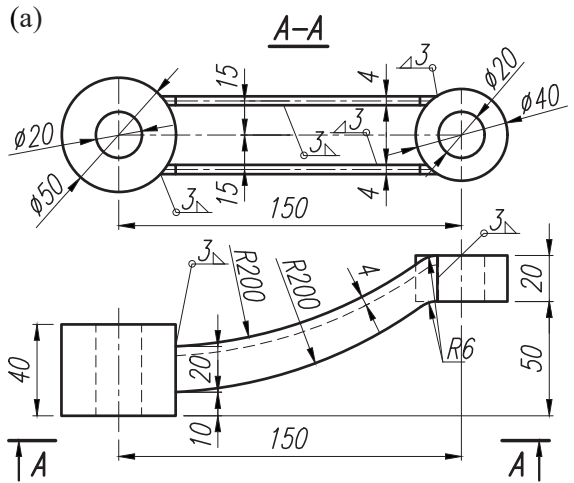

(b)

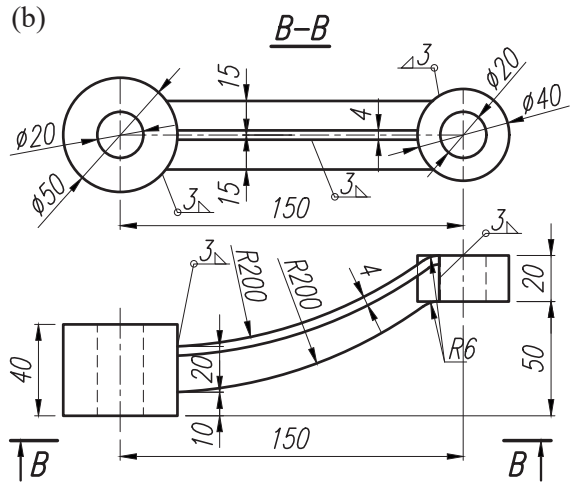

Fig. 1 Single-armed spider: a) connector with C-shape cross-section of the arm, b) connector with T-shape cross-section of the arm

Material properties adopted for both glass plate and spider connector are presented in Table 1. It is worth noting that the glass plates would not be the part of further discussion on numerical results, therefore, a simplified elastic/isotropic model was used instead of real brittle glass material model description. The only aim of creating the glass plate was to accurately transfer the adopted dynamical load to the spider connector.

With respect to the model presented in Fig. 1, the following boundary conditions were adopted for each model:

- the bored hole in lower bushing with the diameter of $\varnothing 50 \mathrm{~mm}$ had both displacements and rotations fixed in $\mathrm{X}$ and $\mathrm{Y}$ direction,

- the bottom surface of the lower $\varnothing 50 \mathrm{~mm}$ bushing had $\mathrm{Z}$ displacement and $\mathrm{X}$ and $\mathrm{Y}$ rotation fixed,

- contact without penetration was set to the top surface of the upper $\varnothing 40 \mathrm{~mm}$ bushing and bottom surface of the glass plate,

- top edge of the hole in the $\varnothing 40 \mathrm{~mm}$ bushing was glued with the bottom edge of the hole in glass plate (glued edge was added in order to prevent glass plate from coming off at the suction load).

Table 1 Material properties of spider connector and glass plate

\begin{tabular}{lcccc}
\hline Model & Material & $\begin{array}{c}\text { Young's } \\
\text { modulus [GPa] }\end{array}$ & $\begin{array}{c}\text { Poisson's } \\
\text { ratio [-] }\end{array}$ & $\begin{array}{c}\text { Density } \\
{\left[\mathrm{kg} / \mathrm{m}^{3}\right]}\end{array}$ \\
\hline Spider & $\begin{array}{c}\text { Steel } \\
\text { S235JR }\end{array}$ & 210 & 0.30 & 7860 \\
Glass Plate & Glass & 70 & 0.23 & 2500 \\
\hline
\end{tabular}

Discretization of both spider connector and glass plate in each model was performed by means of the "3D-Solid" 4-node elements (tetrahedrons). Adaptive mesh density was used to discretize both spider connector and glass plate. For the spider connector, mesh density ranged from $1.5 \mathrm{~mm}$ to $3.0 \mathrm{~mm}$, whereas in the glass plate, this value ranged from $3.0 \mathrm{~mm}$ at the location of the contact with the spider connector to $20.0 \mathrm{~mm}$ on the external edges. Number of nodes and elements for each model are presented in Table 2.

\section{Numerical results and discussion}

In order to record the results of displacements and effective Mises stresses, three different measurement points were defined in the models. The measurement points are presented in Fig. 2.

Global displacements for both pressure and suction were read from the bottom point of the upper $\varnothing 40 \mathrm{~mm}$ bushing (point 1), whereas the Z-displacement was read from the points located at the bottom sides of the upper $\varnothing 40 \mathrm{~mm}$ bushing (points 2, 2R - reflection of the point 2 located on the rear part of the model presented in Fig. 2). In the spider connector with the T-shape arm cross-section, effective stress was read from the web bottom surface connected with the upper $\varnothing 40 \mathrm{~mm}$ bushing, whereas in the C-shape arm cross-section, the value was read from both bottom connections (points 3, 3R - reflection of point 3 located on the rear part of the model presented in Fig. 2). Numerical results for suction are presented in Table 3, whereas the

Table 2 Number of nodes and "3D-Solid" elements in each numerical model

\begin{tabular}{lccc}
\hline $\begin{array}{l}\text { Model (Connector arm } \\
\text { cross-section) }\end{array}$ & Spider connector elements & Glass plate elements & Total number of nodes \\
\hline T-shape & 31708 & 14221 & 12005 \\
T-shape (weld) & 36606 & 14221 & 12898 \\
C-shape & 35724 & 14324 & 12985 \\
C-shape (weld) & 39767 & 14324 & 50827 \\
\hline
\end{tabular}



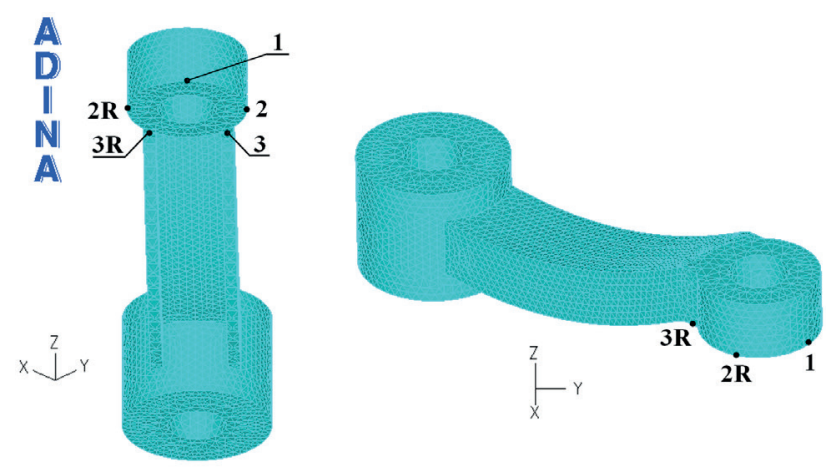

Fig. 2 The measurement points 1-3 adopted for the numerical model of a single-armed spider with C-shaped arm cross-section

value for pressure are shown in Table 4. The maximum stress values presented in the table was read as a maximum for the whole model, whereas no constant point was found.

The results presented in Table 3 and Table 4 show that the maximum stress values and displacements are lower in the C-shape single-arm spider than in the T-shape for both pressure and suction loads. Furthermore, providing fillets that represent welds also reduces the stresses within the section, which is connected with lower corner stress concentration, since smaller radius of a fillet corresponds to higher stresses in this area. Comparison of the T-shape single-armed spider with the C-shape model under suction load $(t=1.2 \mathrm{~s})$, with both numerical models left without weld fillets, showed that maximum von Mises stress obtained for T-shape is around 1.55 times higher than in the $\mathrm{C}$-shape model. With weld fillets added, the difference between the T-shape and C-shape decreased insignificantly to 1.52 times. Furthermore, in order to best utilize the profile, the maximum stress should be slightly lower than the yield stress of S235JR steel (235 MPa). The percentage utilization of S235JR yield stress for each model is presented in Fig. 3. Von Mises stress redistribution plot in the C-shape arm cross-section spider connector without weld fillets under the suction load $(t=1.2 \mathrm{~s})$ is presented in Fig. 4.

The results presented in Fig. 3 demonstrate that the best utilization of the section from the standpoint of the S235JR steel strength was obtained for the T-shape arm cross-section connector. Depending on the T-shape arm cross section (with and without welding fillets), the utilization fits the range of $79-88 \%$. In the C-shape single-armed

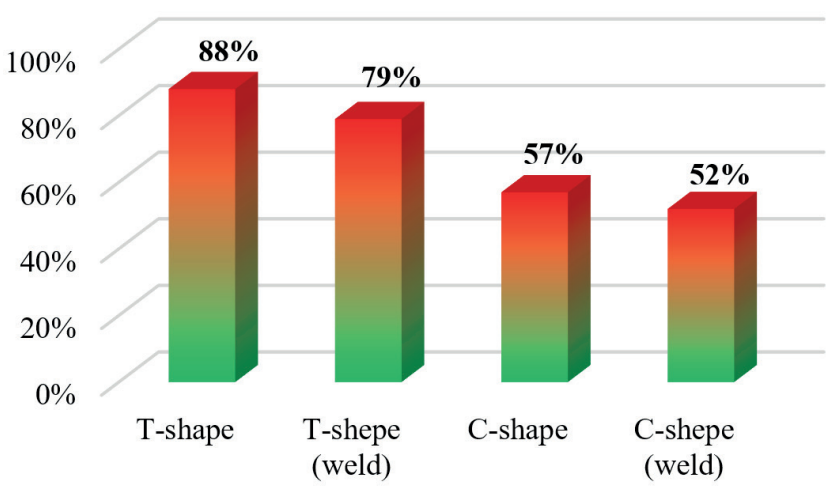

Fig. 3 Comparison of maximum effective stress obtained from the numerical analysis under the suction load $(\mathrm{t}=1.2 \mathrm{~s})$ with maximum yield stress established for S235JR steel

Table 3 Obtained numerical results for each model for suction, $t=1.2 \mathrm{~s}$

\begin{tabular}{|c|c|c|c|c|c|c|c|}
\hline \multicolumn{8}{|c|}{ Suction, $t=1.20 \mathrm{~s}$} \\
\hline \multirow{2}{*}{$\begin{array}{l}\text { Model (Connector } \\
\text { arm cross-section) }\end{array}$} & \multirow{2}{*}{$\begin{array}{c}\text { Max. von Mises } \\
\text { stress }[\mathrm{MPa}] \\
(\text { Point } 1)\end{array}$} & \multirow{2}{*}{$\begin{array}{l}\mathrm{Z} \text { displacement of } \\
\text { free end }[\mathrm{m}] \\
(\text { Point } 1)\end{array}$} & \multirow{2}{*}{$\begin{array}{c}\text { Global } \\
\text { displacement }[\mathrm{m}] \\
(\text { Point } 1)\end{array}$} & \multicolumn{2}{|c|}{$\mathrm{Z}$ displacement $[\mathrm{m}]$} & \multicolumn{2}{|c|}{ Von Mises Stress $[\mathrm{MPa}]$} \\
\hline & & & & Point 2 & Point 2R & Point 3 & Point 3R \\
\hline T-shape & 207.35 & $7.71 \mathrm{E}-05$ & 8.96E-05 & $6.89 \mathrm{E}-05$ & $2.12 \mathrm{E}-05$ & \multicolumn{2}{|c|}{154.44} \\
\hline T-shape (weld) & 185.90 & $7.48 \mathrm{E}-05$ & $8.69 \mathrm{E}-05$ & $7.11 \mathrm{E}-05$ & $1.97 \mathrm{E}-05$ & \multicolumn{2}{|c|}{129.22} \\
\hline C-shape & 133.49 & $6.05 \mathrm{E}-05$ & $6.89 \mathrm{E}-05$ & $6.05 \mathrm{E}-05$ & $2.14 \mathrm{E}-05$ & 117.84 & 98.61 \\
\hline C-shape (weld) & 121.96 & $5.90 \mathrm{E}-05$ & $6.72 \mathrm{E}-05$ & $6.28 \mathrm{E}-05$ & $1.72 \mathrm{E}-05$ & 82.79 & 69.36 \\
\hline
\end{tabular}

Table 4 Obtained numerical results for each model for pressure, $t=3.0 \mathrm{~s}$

\begin{tabular}{|c|c|c|c|c|c|c|c|}
\hline \multirow{3}{*}{$\begin{array}{l}\text { Model (Connector } \\
\text { arm cross-section) }\end{array}$} & \multicolumn{5}{|c|}{ Pressure, $t=3.00 \mathrm{~s}$} & & \\
\hline & \multirow{2}{*}{$\begin{array}{c}\text { Max. von Mises } \\
\text { stress [MPa] } \\
(\text { Point } 1)\end{array}$} & \multirow{2}{*}{$\begin{array}{l}\mathrm{Z} \text { displacement of } \\
\text { free end [m] } \\
(\text { Point } 1)\end{array}$} & \multirow{2}{*}{$\begin{array}{c}\text { Global } \\
\text { displacement }[\mathrm{m}] \\
(\text { Point } 1)\end{array}$} & \multicolumn{2}{|c|}{$\mathrm{Z}$ displacement $[\mathrm{m}]$} & \multicolumn{2}{|c|}{ Von Mises Stress [MPa] } \\
\hline & & & & Point 2 & Point 2R & Point 3 & Point 3R \\
\hline T-shape & 146.60 & $-5.45 \mathrm{E}-05$ & $-6.34 \mathrm{E}-05$ & $-4.87 \mathrm{E}-05$ & $-1.50 \mathrm{E}-05$ & 109.19 & \\
\hline T-shape (weld) & 131.45 & $-5.29 \mathrm{E}-05$ & $-6.15 E-05$ & $-5.03 \mathrm{E}-05$ & $-1.39 \mathrm{E}-05$ & 91.36 & \\
\hline C-shape & 94.48 & $-4.28 \mathrm{E}-05$ & $-4.88 \mathrm{E}-05$ & $-4.28 \mathrm{E}-05$ & $-1.51 \mathrm{E}-05$ & 83.41 & 69.78 \\
\hline C-shape (weld) & 86.35 & $-4.17 \mathrm{E}-05$ & $-4.75 \mathrm{E}-05$ & $-4.45 \mathrm{E}-05$ & $-1.21 \mathrm{E}-05$ & 58.61 & 49.09 \\
\hline
\end{tabular}

* "-" sign in the table denote the displacements opposite to the $\mathrm{Z}$-axis direction 

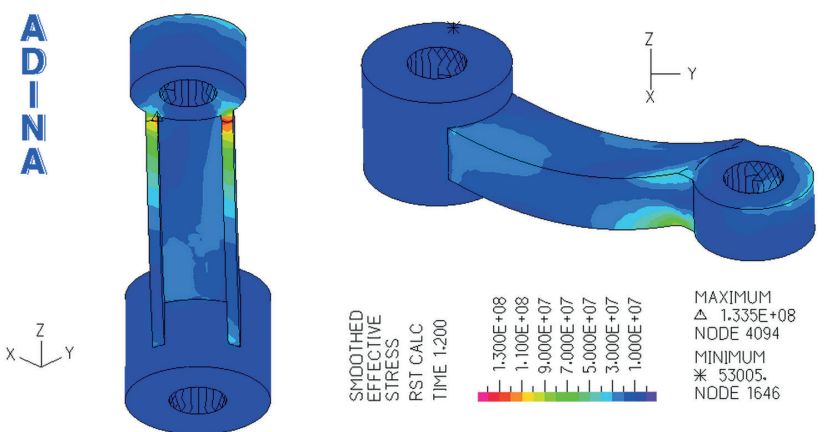

Fig. 4 von Mises stress redistribution plot in the C-shape arm crosssection spider connector under the suction load $(t=1.2 \mathrm{~s})$

connector, the percentage range of yield stress utilization is significantly lower and fits the range of $52-57 \%$. Under the pressure load (see Table 4), the percentage utilization of yield stress would be much lower because the suction load had higher value than the pressure load.

However, the results obtained for stress are important from the standpoint of the Ultimate Limit State and the displacements should be also evaluated. Since glass is a brittle material, displacements should be reduced to minimum, whereas for larger glass plates, some freedom of connector movement should be provided to allow for glass plate displacements. Such a large plate bends significantly under the applied load, which, in the case of connection with a rigid spider, could lead to the development of visible cracks or even breaking near the connection point. The results presented in Table 3, concerning the dominant load (suction), show that the upper bushing rotates slightly around the connector symmetry axis. The differences in the values between points 2 and $2 \mathrm{R}$ for all analyzed numerical models are presented in Fig. 5. Furthermore, Z-axis deformation of the numerical model with T-shape arm cross-section without welding fillets under the pressure load at $t=3.0 \mathrm{~s}$ is presented in Fig. 6 .

The results presented in Fig. 5 show that the maximum difference in displacements for points 2 and $2 \mathrm{R}$ was obtained for the numerical model of the spider with T-shape arm cross-section. It is worth noting that slightly higher difference in this displacement is obtained when weld fillets are added to both models. This is connected with better distribution of internal forces: rotation of the upper bushing was higher, whereas overall stresses were lower (compare spider with $\mathrm{T}$ or $\mathrm{C}$-shape arm cross-section in Table 3 and Table 4) due to lower edge stress concentration. Due to the fact that the dimensions of the glass plate adopted in this paper were $1.50 \times 1.00 \mathrm{~m}$, the plate could be treated as a large glass plate, thus some freedom of rotation

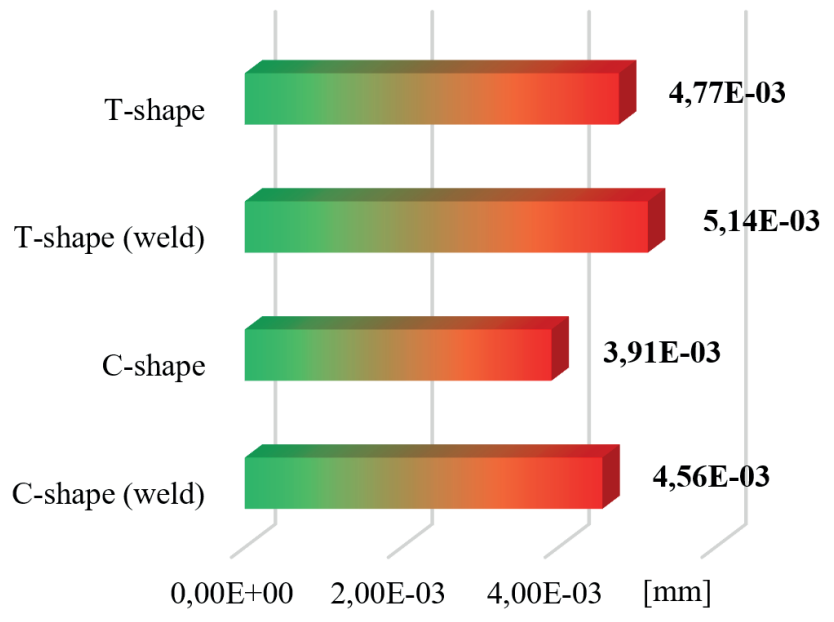

Fig. 5 Difference in Z-axis displacement between points 2 and $2 \mathrm{R}$ in the numerical models with $\mathrm{T}$-shape arm cross section under the pressure load, $t=3.0 \mathrm{~s}$

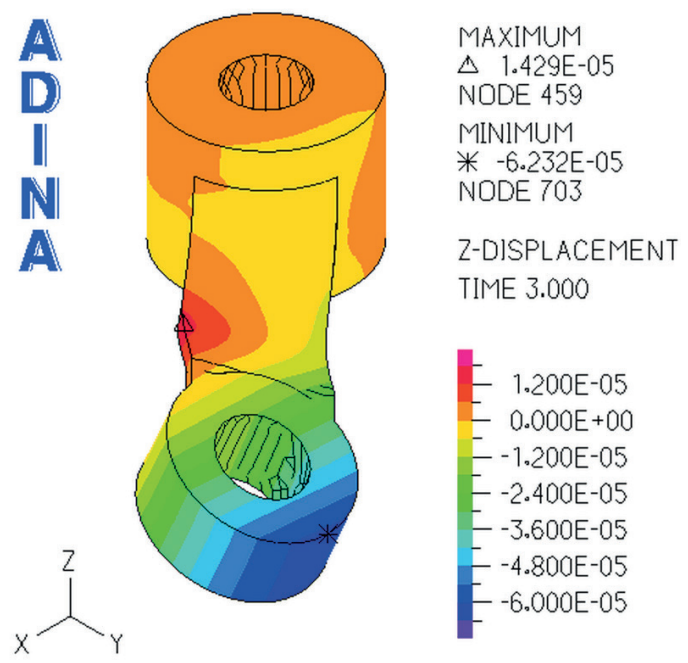

Fig. 6 Deformed spider with T-shape arm cross-section numerical model with 300 times magnification factor. Z-axis displacement plot

was provided for the upper bushing. However, the freedom of rotation of the upper bushing is advisable. Higher values of that rotation within simple connector model correspond to higher maximum stress obtained compared to pure onedirection bending (for example, in the numerical model with T-shape arm cross-section without welding fillets).

\section{Conclusions}

Nowadays, computer-aided design based on the finite element method is commonly used by many researchers to analyze and optimize problems of almost any area of life. The popularity of the FEM method is gradually increasing due to its important advantages [7, 8]. Expensive experimental tests can be replaced with the FEM analysis [9-15], which is less time-consuming while the overall costs of 
such analyses are much lower. Computer-aided engineering is not limited to small objects and structures but can be also utilized to solve complex problems of larger structures. Cajka and Krejsa [16] performed numerical analysis of rooflight steel structure and validated their results with experimental tests, whereas complex numerical analyses of bridge structures were presented in [17-19].

This paper presents numerical analysis of single-arm spider glass fixing with different shapes of connector arm cross-section under the dynamic wind load. It was found that the unfavorable stress distribution from the applied dynamic load on the rectangular glass plate caused both bending and torsion, which consequently led to the increase in the values of stress. Furthermore, the analysis revealed the effect of weld fillets used in the models. The fillets added to represent welds reduced the maximum stress and provided significantly better internal force distribution, which allowed the model to twist over a greater range compared to the numerical model without fillets (see Fig. 5, Table 3 and Table 4).

Displacements and force distribution in joint and clamped glass connectors were also analyzed by Szczerbal et al. [20, 21]. These authors performed numerical analysis of these connectors using the ABAQUS software with

\section{References}

[1] Sedlacek, G., Blank, K. "Glass in structural engineering", Ernst \& Sohn, Berlin, Germany, 1999. (in German)

[2] Fornalczyk, I. "Projektowanie przeszkleń fasad i przekryć dachowych ze szkła strukturalnego", Institute of Civil Engineering - Wroclaw University of Technology, MSc Thesis, 2002. (in Polish)

[3] Bohmann, D. "Numerical analyses of laminated glass", RWTH, Aachen, Germany, PhD Thesis, 1999. (in German)

[4] Sedlacek, G., Gulvanessian, H., Blank, K., Laufs, W. "Glass for Structural Design", John Wiley \& Sons, New York, NY, USA, 2004.

[5] Szczerbal, B., Włochal, D., Glema, A., Łodygowski, T. "Łączniki punktowe w szklanych konstrukcjach" (Point connectors in glass structures), Świat szkła, 1(126), pp. 34-37, 2009. (in Polish)

[6] PKN "PN-EN: 1991-1-4:2008. Eurocode 1. Actions on structures. Part 1-4: General actions - wind actions", The Polish Committee for Standardization, Warsaw, Poland, 2008. (In Polish)

[7] Major, M., Major, I. "Comparative analysis of the distribution of effective stress in Mooney and Zahorski materials using ADINA software", Advanced Materials Research, 1020, pp. 165-170, 2014. https://doi.org/10.4028/www.scientific.net/AMR.1020.165

[8] Major, I., Major, M. "Modeling of wave propagation in the ADINA software for simple elastic structures", Advanced Materials Research, 1020, pp. 171-176, 2014. https://doi.org/10.4028/www.scientific.net/AMR.1020.171 different boundary conditions. Furthermore, the numerical results were validated based on the destructive experimental tests. It was shown that despite some differences in the results of the numerical analysis and experimental tests, the destructive models were exactly the same for both cases. Based on $[20,21]$ and the numerical analysis presented in this paper, it can be emphasized that even small simplifications introduced to the numerical model with respect to the actual state may yield misleading results. It is worth noting that the FEM analyses are always idealized, whereas in experimental tests, other factors (such as microcracks, non-ideally bored holes, temperature etc.) have a significant effect on the results.

The numerical analyses showed that the connector with C-shape arm cross-section would be better from the standpoint of safety, since higher values of load could be transferred, whereas T-shape is more economical, with less welds required and the profile being slightly lighter than the $\mathrm{C}$-shape. Furthermore, the spider with the T-shape arm cross-section had higher range of allowed torsion, which could be critical in larger glass plates. The spider glass connectors are only one of many possible variants and have to be treated as reference models that should be analyzed experimentally prior to the actual use.

[9] Kormaníková, E., Kotrasová, K. "Analysis and optimization of laminated circular cylindrical shell", WSEAS Transactions on Applied and Theoretical Mechanics, 12, pp. 163-172, 2017.

[10] Major, M., Major, I. "Acceleration Wave in a Thin Segmental Hyperelastic Rod", Archives of Civil and Mechanical Engineering, 10(1), pp. 59-67, 2010. https://doi.org/10.1016/S1644-9665(12)60130-7

[11] Kormaníková, E., Kotrasová, K. "Finite element analysis of damage modeling of fiber reinforced laminate plate", Applied Mechanics and Materials, 617, pp. 247-250, 2014.

https://doi.org/10.4028/www.scientific.net/AMM.617.247

[12] Major, M., Major, I., Różycka, J. "Propagation of the surface of a strong discontinuity in the hyperelastic materials", Advanced Materials Research, 1020, pp. 188-192, 2014. https://doi.org/10.4028/www.scientific.net/AMR.1020.188

[13] Major, M., Kuliński, K., Major, I. "Dynamic analysis of an impact load applied to the composite wall structure", MATEC Web of Conferences, 107(55), Article number: 00055, 2017. https://doi.org/10.1051/matecconf/201710700055

[14] Major, I., Major, M., Respondek, Z. "Dynamical analysis of steel point connectors used for fixation of glass façades", Archives of Metallurgy and Materials, 63(1), pp. 491-496, 2018. https://doi.org/10.24425/118966 
[15] Major, I., Major, M. "Traveling waves in a thin layer composed of nonlinear hyperelastic Zahorski's material", Journal of Theoretical and Applied Mechanics, 47(1), pp. 109-126, 2009. [online] Available at: http://www.ptmts.org.pl/jtam/index.php/jtam/article/ download/v47n1p109/295

[16] Cajka, R., Krejsa, M. "Validating a computational model of a rooflight steel structure by means of a load test", Applied Mechanics and Materials, 501-504, pp. 592-598, 2014.

https://doi.org/10.4028/www.scientific.net/AMM.501-504.592

[17] Melcer, J., Lajčáková, G. "Comparison of finite element and classical computing models of reinforcement pavement", Advanced Materials Research, 969, pp. 85-88, 2014.

https://doi.org/10.4028/www.scientific.net/AMR.969.85

[18] Vican, J., Sykora, M. "Numerical analysis of the bridge orthotropic deck time dependent resistance", Komunikacie, 15, pp. 112-117, 2013. [online] Available at: http://komunikacie.uniza.sk/index.php/ communications/article/view/698/663
[19] Koteš, P., Vičan, J., Brodnan, M., Nikolič, R. "Reliability of Existing Concrete Bridges from the Aspect of the Reinforcement Corrosion", Key Engineering Materials, 691, pp. 119-128, 2016. https://doi.org/10.4028/www.scientific.net/KEM.691.119

[20] Szczerbal B., Włochal D., Glema A., Łodygowski T. "Analiza numeryczna konstrukcji szklanych mocowanych punktowo. Część 1" (Numerical analysis of point-mounted glass structures, Part 1), Świat szkła, 4(129), pp. 24-26, 2009. (in Polish)

[21] Szczerbal B., Włochal D., Glema A., Łodygowski T. "Analiza numeryczna konstrukcji szklanych mocowanych punktowo. Część 2" (Numerical analysis of point-mounted glass structures, Part 2), Świat szkła, 6(131), pp. 34-37, 2009. (in Polish) 